\title{
Weitere Beiträge zur Kenntnis von Kunsthonigen.
}

\author{
Von \\ Dr. A. Jägerschmid. \\ Mitteilung aus dem Chemischen Laboratorium des Polytechnischen \\ Instituts Straßburgi. Els. (Direktor: Dr. Hänle.)
}

[Eingegangen an 8. Mai 1909.]

In meiner Arbeit über Kunsthonige ${ }^{1}$ ) sprach ich die Vermutung aus, daß die Resorcin- wie Aceton-Salzsäure-Reaktion bei Kunsthonigen infolge von Caramelbildung bei der Invertzuckerfabrikation eintrete. Meine weiteren Untersuchungen haben nun ergeben, daß die charakteristischen Farbenreaktionen von dem bei der Invertiexung des. Zuckers entstehenden, auch im Caramel enthaltenen Furfurol, bezw. Methylfurfurol und hauptsächlich Oxymethylfurfurol herrühren ${ }^{2}$ ).

Da diese Furfurole mit Wasserdämpfen flüchtig sind, so destillierte ich die etwa. im Honig vorhandenen flüchtigen Bestandteile mit Wasserdämpfen über; hierbei machten sich folgende Erscheinungen bemerkbar: Die Destillate der rein en Honige zeigten, mit Anilinacetat versetzt (Anilin und konz. Essigsäure etwas im ÜberschußB), keine Rotfärbung, während die Destillate der Kunsthonige mit Anilinacetat versetzt schöne rote Färbungen ergaben. Die Reaktion läbt sich am besten beobachten, wenn man einige ccm des zuerst übergehenden Destillates mit 2-4 ccm Anilinacetat. in einem Reagensglase übergießat.

Selbst im Destillate von Handelsglykose und auch in deren Mischung mit 75\% echtem Blütenhonig ließ sich deutlich mit Anilinacetat Oxymethylfurfurol nachweisen.

Die Destillate der reinen Bienenhonige hatten ein angenehmes Honigaroma, die der Kunsthonige híngegen ließen ein solches nicht wahrnehmen. Spelztroskopisch untersucht, zeigt Anilinacetat, in etwas Wasser gelöst, im Spektrum kein verändertes Bild.

Ebenso verhält sich das mit Anilinacetat versetzte Destillat der reinen Bienenhonige. Bei Kunsthonigen tritt beim Versetzen des Destillates mit Anilinacetat manchmal sofort, manchmal erst nach einer halben bis einer Minute deutliche Rotfärbung auf, die nach ungefähr 15 Minuten verschwinden kann, jedoch auf Zusatz von etwas Essigsäure wieder schwach hervortritt. Bei der Untersuchung im Spektroskop beobachtet. man folgendes:

Rot wird mehr karmoisinrot, dann folgt ein gelber Strich und dann ein dunkelolivgrüner Streifen. Blau verschwindet beinahe und geht in Blauschwarz über.

Werden Kunsthonige (Invertzuckerhonige) mit Aceton ausgezogen und der Acetonauszug mit Salzsäure versetzt, so tritt, wie schon früher mitgeteilt, Rotfärbung ein.

Spektroskopisch untersucht, zeigt die Flüssigkeit folgendes Bild: Auf Rot folgt ein breiter schwarzer Strich, dann folgen Grün und Blau.

Bei der Verdünnung mit Essigsäure geht der breite schwarze Strich in Dunkelolivgrün über.

1) Diese Zeitschrift 1909, 17, 118.

2) Vergl. D üll in Chem.-Ztg. 1895, 19, 216 .

3) v. Lippmann, Die Chemie der Zuckerarten. 1895, 1105. 
Die Acetonauszüge der reinen Honige, mit Salzsäure versetzt, verändern das Spektrum nicht; erst nach längerem Stehen treten infolge ihrer Zersetzung Veränderungen ein.

Zum Schlusse möchte ich noch bemerken, daß das Aceton vollkommen rein sein muß ; mit Salzsäure übergossen, darf es sich höchstens gelb färben.

\title{
Über Kirschsaft.
}

\author{
Von \\ P. Buttenberg und P. Berg. \\ Mitteilung aus dem Statlichen Hygienischen Institut zu Hamburg. \\ [Eingegangen am 12. Mai 1909.]
}

Die am meisten geübte Verfälschung der Fruchtsäfte besteht in der Streckung nit Wasser. Wird Himbeersaft mit Wasser oder - was in der Wirkung im wesentlichen auf dasselbe hinausläuft - mit sog. Nachpresse vermischt, so tritt eine Herabsetzung der für die Güte des Fruchtsaftes charakteristischen schön roten Färbung ein. Um diese dem Käufer auffallende Veränderung des Aussehens zu verdecken, wird der Himbeersaft „mit Kirschsaft gedunkelt"s oder mit Anilin-, Flechten- und anderen Farbstoffen versetzt. Beim Kirschsafte liegen die Verhältnisse erheblich anders. Seine Färbung ist eine derartig kräftige, daß eine nicht zu übertriebene Verdünnung kaum in die Augen fällt; ein Verdacht erregender fremder Farbstoff, den der Chemiker schon bei der qualitativen Prüfung findet, braucht nicht zugefügt zu werden. So kommt es denn auch, daß viele Kirschsäfte des Handels gestreckt, aber nicht künstlich gefärbt sind.

Von den in den Jahren 1907 und 1908 in Hamburg aus dem Verkehr entnommenen Kirschsäften waren 12 gewässert bezw. mit Nachpresse versetzt; aber nur einer von diesen, der allerdings der Hauptsache nach ans zugefügtem Wasser bestand, verdankte sein tief kirschrotes Aussehen fast ausschließlich einem Anilinfarbstoffe. Bei der Abgabe im Kleinhandel hatten die Verkäufer wiederholt die gestreckten Kirschsäfte als solche kenntlich gemacht, doch war auch in verschiedenen Fällen diese Deklaration auf dem Wege vom Fabrikanten zum Konsumenten verloren gegangen oder überhaupt von vornherein unterblieben.

Für die Beurteilung der stattgefundenen Wässerung ist es erforderlich, Zahleninaterial über die Zusammensetzung von einwandfreien Kirschsäften zur Hand zu haben. Die Fruchtsaftstatistilk dieser Zeitschrift hat meist regelmäßig auch Angaben über Kirschsäfte ${ }^{1}$ ) gebracht. Forscht man nach, wie die Autoren die untersuchten Säfte bereitet und weiter behandelt haben, so ergibt sich fast durchweg die gleiche Arbeitsweise: Die Kirschen sind mit oder ohne Kerne zerquetscht und nach dem

1) Diese Zeitschrift 1904, 8, 666; 1905, 10, 718 und $736 ; 1906,12,731 ; 736$ und 742; $1908,15,134,142$ and 158. 